\title{
EFFECT OF IMPLANTING A PASSIVE INTEGRATED TRANSPONDER TAG IN JUVENILE CHUB, SQUALIUS CEPHALUS (L.), ON THEIR CONDITION, GROWTH AND SURVIVAL
}

\author{
PETRA HORKÁ ${ }^{1, *}$, PAVEL HORKÝ², and OND ŘJ SLAVÍK² \\ ${ }^{1}$ Institute for Environmental Studies, Faculty of Science, Charles University, Benátská 2, 128 01, Prague 2, Czech Republic \\ 2 Department of Zoology and Fisheries, Faculty of Agrobiology, Food and Natural Resources, Czech University of Life Sciences Prague, \\ 165 21, Prague 6, Czech Republic \\ *Corresponding author: petra.horka@natur.cuni.cz
}

\section{ABSTRACT}

The effect of implanting a Passive Integrated Transponder (PIT) tag on the survival, growth and condition of a small cyprinid, juvenile chub Squalius cephalus (L.) with a mean weight of $2.4 \mathrm{~g}$ was studied in the laboratory. During this experiment, which lasted for 31 days, 80 specimens were tagged. The changes in Fulton's condition factor $(K)$, specific growth rate of mass $\left(G_{M}\right)$ and specific increase in length $\left(L_{S}\right)$ were evaluated. The results showed that implanting PIT tags did not affect the survival or growth of the fish; however, it had a negative effect on their condition. The initial size of the fish had a significant effect on the specific growth rate in terms of mass, but not in terms of length. Survival was $98.8 \%$ and tag retention $97.5 \%$, when the tag made up $4.3 \%$ of the mass of the fish. These results demonstrate that PIT tagging is an appropriate method for chub heavier than $2 \mathrm{~g}$. For this size category, we recommend that PIT tagging is suitable when the tag makes up $4.3 \%$ of the body mass of the individuals.

Keywords: condition; cyprinids; PIT tags; specific growth rate; tagging effect

\section{Introduction}

Passive integrated transponder (PIT) tags are used increasingly in both commercial aquaculture and ecological studies on fish (Alanärä et al. 2001; Fischer et al. 2001; Bolland et al. 2009a; Grieve et al. 2018). PIT tagging has become one of the most effective tools for identification of individuals and, due to their relatively low cost and automatic data collection options, they enable a large number of fish to be marked and detected with high reliability. Furthermore, the weight and size of PIT tags make them ideal for studying juveniles or small species of fish (Thorstad et al. 2013; Jørgensen et al. 2017). Although this tagging method is almost universally applicable, size and species-specific adverse effects have been reported (Roussel et al. 2000; Pennock et al. 2016). Careful evaluation of the effects of PIT tagging on a wide range of fish of different sizes is urgently required (Ficke et al. 2012).

Juvenile cyprinids weighing only a few grams have received little attention in this context. For cyprinids, tag retention and the survival of tagged individuals has been evaluated previously for the genus Squalius (e.g. Bolland et al. 2009b; Pires et al. 2010). For example, Bolland et al. (2009b) report the effects of PIT tags in terms of mortality and retention in large Squalius cephalus (L.). In the study of Pires et al. (2010) survival, tag retention and swimming performance are evaluated for an endangered Iberian cyprinid, Mira chub Squalius torgalensis (Coelho et al. 1998). The objective of the present study was to extend the work on small cyprinids, focusing on both retention and survival, and growth, weight and condition of juvenile chub Squalius cephalus (L.) after implanting PIT tags.

\section{Materials and Methods}

Chub is a common omnivorous cyprinid inhabiting European rivers, with a wide ecological amplitude and known migratory and daily activity patterns (Lucas and Baras 2000). The fish used in this experiment were hatchery-reared juvenile chub, Squalius cephalus (L.), obtained from a local fish supplier (Czech Fishery Ltd., Czech Republic). A total of 160 fish of a similar size were randomly distributed among four separate holding tanks (300 l each; natural photoperiod; conditions in all tanks: temperature $19.1 \pm 0.5^{\circ} \mathrm{C}$; conductivity $314 \pm 6.9 \mu \mathrm{S} \mathrm{cm}^{-1}$ ) and acclimated for 3 weeks prior to the start of the experiment. Fish were fed daily with dry fish flake food. In order to ensure good water quality, one third of the water in each tank was changed each week.

Fish from two randomly selected holding tanks ( 80 specimens) were tagged at the beginning of the experiment, after first anaesthetising them with 2-phenoxy-ethanol (0.2 $\mathrm{ml} \mathrm{l}^{-1}$; Merck KGaA, Germany). Fish were measured $\left(\mathrm{L}_{S}\right.$; standard length, mean $54 \mathrm{~mm}$, range 47-64 mm), weighed ( $\mathrm{M}$; mean body mass $2.37 \mathrm{~g}$, range $1.44-4.24 \mathrm{~g}$ ), and then PIT tags (Trovan ID100, $0.1 \mathrm{~g}$ in air, $12 \times 2.1 \mathrm{~mm}$ ) were inserted into the abdominal cavity using a hypodermic needle attached to a syringe. The tag to body mass ratio varied from 2.36 to $6.95 \%$ (mean 4.25\%). The fish placed in the two other holding tanks were left undisturbed to serve as controls (Skov et al. 
Table 1 The initial and final lengths $\left(L_{S}\right)$, masses $(M)$ and condition $(K)$ of PIT tagged and control specimens of chub, Squalius cephalus.

\begin{tabular}{|l|c|c|c|c|c|c|}
\hline Treatment & Mean \pm S.E. & Mean \pm S.E. & Mean \pm S.E. & Mean \pm S.E. & Mean \pm S.E. & Mean \pm S.E. \\
\hline Control & initial $\mathbf{L}_{\mathbf{s}}(\mathbf{m m})$ & final $\mathbf{L}_{\mathbf{s}}(\mathbf{m m})$ & initial $\mathbf{M}(\mathbf{g})$ & final $\mathbf{M}(\mathbf{g})$ & initial K & final K \\
\hline PIT tags & & $56.3 \pm 0.4$ & & $2.92 \pm 0.06$ & & $1.63 \pm 0.01$ \\
\hline
\end{tabular}

2005). During the experimental period, which lasted for 31 days, all fish were kept under the same regime with daily monitoring to detect tag expulsion or death. At the end of the experiment, all fish were anaesthetised, measured and weighed. All experimental procedures complied with relevant legislative regulations (Law no. 246/1992, $\$ 19$, art. 1, letter c).

The specific growth rate (GM) in terms of mass (proportional increase/day) was calculated according to the formula: $G M=100\left(\ln M_{2}-\ln M_{1}\right) t^{-1}$, where $\mathrm{M}_{1}$ and $\mathrm{M}_{2}$ are the masses (g) at the start and end of the study period, respectively, and $t$ is the length of the period in days. The increase in $\mathrm{L}_{\mathrm{S}}(\mathrm{GL})$ was calculated similarly (Jepsen et al. 2008). The changes and differences in Fulton's condition factor $(\mathrm{K})$ were evaluated as: $K=M L_{S}{ }^{-3}$, where $\mathrm{M}$ is mass and $\mathrm{L}_{\mathrm{S}}$ is the standard length $(\mathrm{mm})$.

Statistical analyses were performed using the SAS software package (SAS Institute Inc., version 9.2, www .sas.com). Standard length, mass, Fulton's condition factor, specific growth rate and increase in length were analysed using separate mixed models with random factors (PROC MIXED). Random effects were used to account for repeated measures collected for the same experimental units (individual fish) throughout the duration of the study. The significance of an exploratory variable (i.e., tagging treatment) in a particular model was assessed using a F-test. Differences between the classes were tested using a t-test (Tukey-Kramer adjustment for multiple comparisons) and the degrees of freedom calculated using the Kenward-Roger method.

\section{Results}

The smallest individual $(1.44 \mathrm{~g})$ in which a PIT tag was implanted died the following day. Post mortem examination revealed contusion of the internal organs. The remaining 79 tagged fish survived, resulting in a survival of $98.8 \%$. One fish $(1.75 \mathrm{~g})$ expelled its tag during the third week of the experiment, so tag retention was $97.5 \%$.

The PIT tagged fish grew significantly (mass $\mathrm{F}_{2,135}=90.99, p<0.0001$, Fig. 1a; length $\mathrm{F}_{2,137}=149.3$, $p<0.0001$, Fig. 1b) during the experimental period, and their final size did not differ from that of the control fish (mass Adj $p>0.63$; length Adj $p>0.54$, Table 1), indicating that PIT tagging did not affect the growth of the juvenile chub. The condition of the PIT tagged fish remained the same throughout the experiment $\left(\mathrm{F}_{2,138}=16.52\right.$, $p<0.0001$, Adj $p>0.66$, Fig. 1c), but was poorer at the end of the experiment than that of the control fish (Adj $p<0.0001$ ), which indicates that PIT tagging had a negative effect on fish condition. The tag to body mass ratio had a significant effect on growth in mass $\left(\mathrm{F}_{1,75}=3.66, p<0.05\right.$, Fig. 2$)$, but not on increase in length $\left(\mathrm{F}_{1,75}=0.19, p>0.66\right)$; i.e. smaller fish had a higher specific growth rate of mass.
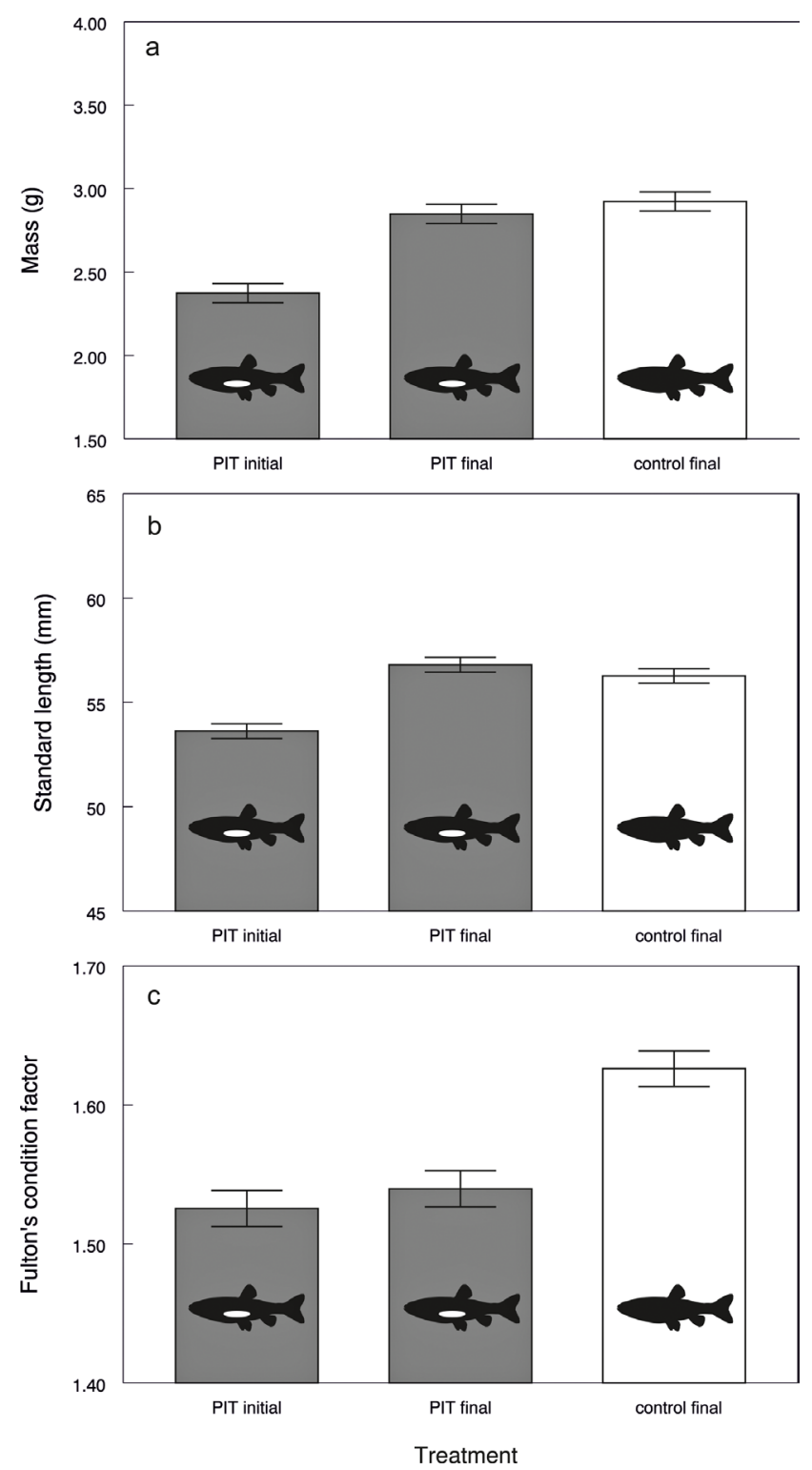

Fig. 1 Initial and final mass (a), length (b) and condition (c) of tagged and control chub. Initial and final values for PIT tagged chub, Squalius cephalus, and final values for control fish are adjusted means \pm SE. 


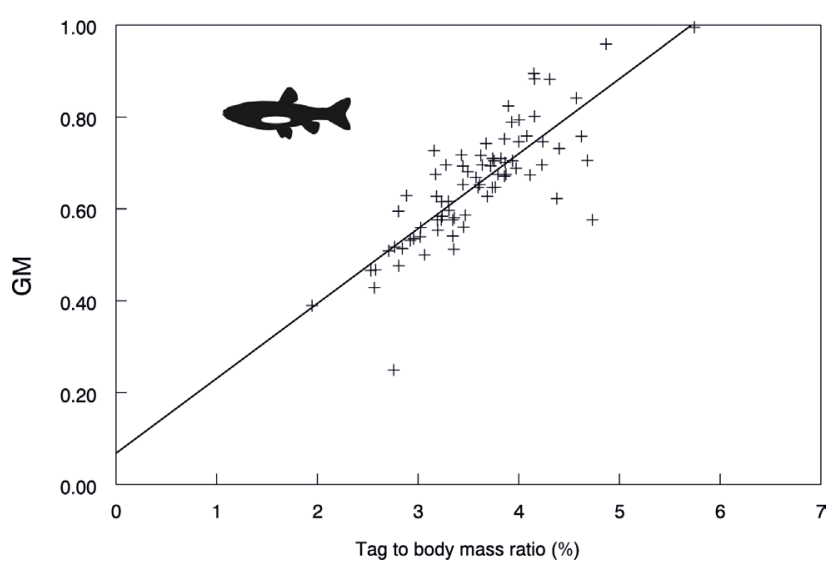

Fig. 2 Relationship between specific growth rate of mass (GM) and the tag to body mass ratio in juvenile chub, Squalius cephalus.

\section{Discussion}

Small fish are more likely to suffer adverse effects from tagging (Jepsen et al. 2008). Based on the present study, it is recommended that the minimum weight for tagging chub with PIT tags is 2 grams, as no fish above this weight lost the tag or died during the experimental period. Tag retention and survival of tagged fish is closely associated with the tag to body mass ratio (Pennock et al. 2016). In order to minimize the effect of tagging a tag to body mass ratio of less than $2 \%$ is often recommended when determining the minimum size of fish to be tagged (Winter 1983; Jepsen et al. 2005). Although this ratio is still used, a number of recent studies have challenged this view and report no or minimal effects of tag to body mass ratios of up to $10 \%$ (Ficke et al. 2012; Ward et al. 2015; Pennock et al. 2016). In this study, juvenile chub implanted with tags that made up $4.3 \%$ of their mass were successfully tagged and $98.8 \%$ survived with negligible effects. Other studies assessing survival and tag retention by small cyprinids under laboratory conditions report tags that make up to $3.94 \%$ of the mass of the fish result in acceptable levels of post-implantation survival (e.g. Skov et al. 2005; Bolland et al. 2009a; Ficke et al. 2012; but see Pennock et al. 2016). All of the flathead chub, Platygobio gracilis, implanted with PIT tags that made up 3.94\% of their mass survived (Richardson 1836) (Ficke et al. 2012), 96.3\% of European chub implanted with tags that made up 2-6\% of their mas survived (Bolland et al. 2009a) and 99\% of roach, Rutilus rutilus (L.), implanted with tags that made up $2.91 \%$ of their mass survived. The higher tag to body mass ratios used in some other studies, e.g. 3.8\% for creek chub (Bangs et al. 2013), 6.3\% for southern redbelly dace, Chrosomus erythrogaster (Rafinesque 1820) (Pennock et al. 2016) and up to $12.5 \%$ for humpback chub Gila cypha (Miller 1946) (Ward et al. 2015), however, are associated with significant reductions in survival (survival between $62.5 \%$ and $82 \%$ ).
At the end of this study, the condition of PIT tagged chub was poorer than that of the controls. This could be a consequence of the energetic costs associated with recovering from the effects of the operation (Jepsen et al. 2008), but the handling and the surgery could also have influenced the observed trends. Capture and handling stress may have different effects on different species of fish. For example, Skov et al. (2005) reports it did affect the condition of PIT tagged rudd, Scardinius erythrophthalmus (L.), but not roach Rutilus rutilus (L.). The weight of tagged Mira chub (Pires et al. 2010) is also lighter 30 days post tagging. Our results indicate that it is possible to implant PIT tags in small cyprinids weighing more than $2 \mathrm{~g}$. For this size category we recommend the tag should not make up more than $4.3 \%$ of the mass of the fish.

\section{Acknowledgements}

The authors wish to thank Dr. John Iwan Jones and Prof. A.F.G. Dixon for correcting the English. This study was financially supported by the Czech Science Foundation (grant No. 16-06498S).

\section{REFERENCES}

Alanärä A, Burns MD, Metcalfe NB (2001) Intraspecific resource partitioning in brown trout: the temporal distribution of foraging is determined by social rank. J Anim Ecol 70: 980-986.

Bangs BL, Falcy MR, Scheerer PD, Clements S (2013) Comparison of three methods for marking a small floodplain minnow. Anim Biotelem 1: 18. doi: 10.1186/2050-3385-1-18.

Bolland JD, Cowx IG, Lucas MC (2009a) Dispersal and survival of stocked cyprinids in a small English river: comparison with wild fishes using a multi-method approach. J Fish Biol 74: 2313-2328.

Bolland JD, Cowx IG, Lucas MC (2009b) Evaluation of VIE and PIT tagging methods for juvenile cyprinid fishes. J Appl Ichthyol 25: 381-386.

Ficke AD, Myrick CHA, Kondratieff MC (2012) The effects of PIT tagging on the swimming performance and survival of three nonsalmonid freshwater fishes. Ecol Eng 48: 86-91.

Fischer P, Kautz H, Weber H, Obergfell W (2001) The use of passive integrated transponder systems (PIT) triggered by infrared-gates for behavioural studies in nocturnal, bottom-dwelling fish species. J Fish Biol 58: 295-298.

Grieve B, Baumgartner LJ, Robinson W, Silva LGM, Pomorin K, Thorncraft G, Ning N (2018) Evaluating the placement of PIT tags in tropical river fishes: a case study involving two Mekong River species. Fish Res 200: 43-48.

Jepsen N, Mikkelsen JS, Koed A (2008) Effects of tag and suture type on survival and growth of brown trout with surgically implanted telemetry tags in the wild. J Fish Biol 7: 594-602.

Jepsen N, Schreck C, Clements S, Thorstad EB (2005) A brief discussion on the $2 \% \mathrm{tag} / \mathrm{body}$ mass rule of thumb. In: Spedicato MT, Lembo G, Marmulla G (eds) Aquatic telemetry: advances and applications. Food and Agriculture Organization of the United Nations, Coispa, Rome, pp 255-259. 
Jørgensen MGP, van Deurs M, Butts IAE, Jørgensen K, Behrens JW (2017) PIT-tagging method for small fishes: A case study using sandeel (Ammodytes tobianus). Fish Res 193: 95-103.

Lucas MC, Baras E (2000) Methods for studying the spatial behaviour of freshwater fishes in the natural environment. Fish Fish 1: 283-316.

Pennock CA, Frenette BD, Waters MJ, Gido KB (2016) Survival of and tag retention in southern redbelly dace injected with two sizes of PIT tags. N Am J Fish Manage 36: 1386-1394.

Pires D, Ribeiro F, Magalhaães MF (2010) Evaluation of PIT-tagging in an endangered Iberian cyprinid. J Appl Ichthyol 26: 612-613.

Roussel J-M, Haro A, Cunjak RA (2000) Field test of a new method for tracking small fishes in shallow rivers using passive inte- grated transponder (PIT) technology. Can J Fish Aquat Sci 57: 1326-1329.

Skov C, Brodersen J, Bronmark C, Hansson L-A, Hertonsson P, Nilsson PA (2005) Evaluation of PIT-tagging in cyprinids. J Fish Biol 67: 1195-1201.

Thorstad EB, Rikardsen AH, Alp A, Økland F (2013) The use of electronic tags in fish research - an overview of fish telemetry methods. Turk J Fish Aquat Sc 13: 881-896.

Ward DL, Persons WR, Young KL, Stone DM, Vanhaverbeke DR, Knight WK (2015) A laboratory evaluation of tagging-related mortality and tag loss in juvenile humpback chub. N Am J Fish Manage 35: 135-140.

Winter JD (1983) Underwater biotelemetry. In: Nielsen LA, Johnsen JD (eds) Fisheries Techniques. Bethesda, Maryland, American Fisheries Society, pp 371-395. 